\title{
The self-confidence levels of senior dental students during endodontic treatment procedures
}

\author{
Tuba Ayhan, Güher Barut, Jale Tanalp \\ Department of Endodontics, Yeditepe University Faculty of Dentistry, Istanbul
}

\begin{abstract}
Objective: The aim of present study was to obtain information from senior dental students enrolled in Yeditepe University Faculty of Dentistry related to their confidence levels during endodontic treatment procedures.
\end{abstract}

Methods: Anonymous survey forms were distributed to 40 senior dental students enrolled in Yeditepe University Faculty of Dentistry. They were asked to indicate their self confidence level by Lickert's scoring system ranging between 1 and 5 .

Results: Retreatment procedure was a treatment type in which $15 \%$ of the students reported as having very little confidence. The majority of the students (67.5\%) felt confident about taking radiographs during endodontic treatment. Meanwhile, irrigation was a procedure in which students felt high level of confidence (82.5\%). Retrieval of broken instruments was determined as a procedure that was not experienced by $65 \%$ of the students.

Conclusion: Further research comprising other schools is warranted to identify the weak areas during endodontic treatment in order to bring resolutions for the delivery of skills during endodontic procedures.

Keywords: Endodontic procedure steps; endodontics; self-confidence, senior students.

Students generally believe that dentistry is one of the $\checkmark$ most difficult programs which necessitates altruism, and financial resources and includes stressful factors such as frequent examinations, maintenance of a sound patientstudent relationship and successful clinical application of theoretical knowledge.

Endodontic treatment could be one of the most difficult dental procedures within the field of dentistry. Anatomical complexities of root canals, necessity to ensure sufficient care to the patients and inadequate self-confidence of students are the major factors that contribute to students' decision about endodontics being one of the most difficult disciplines. These realities require dental students to be equipped with knowledge as well as experience satisfactorily while they work independently. ${ }^{[1]}$

Following graduation, dental students should be able to make an accurate diagnosis as regards to endodontic cases and organize a proper treatment plan to carry out a qualified endodontic treatment. ${ }^{[2]}$

The aim of present survey was to gather information from senior dental students enrolled in Yeditepe University Faculty of Dentistry related to their confidence levels during endodontic treatment procedures. 


\section{Materials and methods}

in the study. Anonymous survey forms were distributed to the students and they were not held obliged for completing or returning the survey forms. The questionnaires included questions on previous endodontic procedures performed by the students as well as questions about their self-confidence levels regarding various steps of endodontic procedures.

Self confidence level was indicated by Lickert's scoring system ranging between 1 and 5,1 corresponding to very confident and 5 corresponding to very little confidence. In case students selected scores other than 1 , they were also asked to indicate the types of teeth in which they felt difficulty.

\section{Statistical analyses}

Statistical analyses were performed with NCSS (Number Cruncher Statistical System) 2007 Statistical Software (Utah, USA) in this study. Descriptive statistical methods (frequency and percentage distributions) were used to evaluate the data.

\section{Results}

Among 50 students who were handed out the survey; 40 students $(80 \%)$ returned the forms.

Table 1 and Table 2 summarize the answers given by the students.

Retreatment procedure was a treatment type in which $15 \%$ of the students reported as having very little confidence. The procedure in which students felt the highest level of confidence was root canal irrigation for which $82.5 \%$ of the students scored as very confident. On the other hand, $65 \%$ of the students reported that they had never performed retrieval of broken instruments from the root canal.

\section{Discussion}

This article aimed to understand the difficulties that the senior dental students encountered when performing root canal treatment. Repeated evaluation and feedback from students is important to improve the curriculum and correct the existing mistakes and missing parts. ${ }^{[3]}$ Student questionnaires are significant tools in collecting data for their educational requirements. ${ }^{[1,2]}$

In the dental school where the present study was conducted, the curriculum is dedicated to both theoretical and clinical practice. Clinical portion of the curriculum comprises a significant portion of the overall program during the $5^{\text {th }}$ year as students should be given the op-
Table 1. Confidency percentages related to the steps of endodontic treatment

Achievement of anesthesia Very confident 37.50 Confident Neutral Little confidence

42.50

12.50

Placement of rubber dam Very confident 7.50

Confident

Neutral

Little confidence

Very little confidence

Finding root canal orifices Very confident

Confident

Neutral

Little confidence

Very little confidence

Using rotary instruments

Very confident

Confident

Neutral

Little confidence

Very little confidence

27.50

$18 \quad 45.00$

$5 \quad 12.50$

$3 \quad 7.50$

$3 \quad 7.50$

Taking periapical radiograph

Very confident

Confident

Neutral

Little confidence

Very little confidence

25.00

42.50

17.50

12.50

2.50

50.00

20.00

15.00

5.00

10.00

22.50

67.50

2.50

5.00

2.50

Removing broken instruments from root canals

Very confident

Neutral

Little confidence

Very little confidence

No experience

Retreatment

Very confident

Confident

Neutral

Little confidence

Very little confidence

No experience

5.00

2.50

15.00

12.50

65.00

20.00

25.00

22.50

10.00

15.00

7.50

Obturation of root canals

Very confident

42.50

Confident

37.50

Neutral

Little confidence

Very little confidence

5.00

10.00

5.00

Irrigation of root canals

Very confident

82.50

Confident

17.50

Restoration of endodontically treated teeth

Very confident

Confident

70.00

Neutral

22.50

7.50 
Table 2. Confidence percentages of endodontic prodecures among groups of teeth

\begin{tabular}{|c|c|c|}
\hline & $\mathbf{n}$ & $\%$ \\
\hline \multicolumn{3}{|c|}{ Achievement of anesthesia } \\
\hline Upper Molar & 1 & 4.00 \\
\hline Lower Molar & 24 & 96.00 \\
\hline \multicolumn{3}{|c|}{ Placement of rubber dam } \\
\hline Upper Molar & 19 & 65.52 \\
\hline Lower Molar & 10 & 34.48 \\
\hline \multicolumn{3}{|c|}{ Finding root canal orifices } \\
\hline Upper Premolar & 1 & 3.33 \\
\hline Upper Molar & 24 & 80.00 \\
\hline Lower Molar & 5 & 16.67 \\
\hline \multicolumn{3}{|c|}{ Using rotary instruments } \\
\hline Upper Molar & 12 & 75.00 \\
\hline Lower Premolar & 1 & 6.25 \\
\hline Lower Molar & 3 & 18.75 \\
\hline \multicolumn{3}{|c|}{ Taking periapical radiograph } \\
\hline Upper Anterior & 3 & 9.68 \\
\hline Upper Premolar & 3 & 9.68 \\
\hline \multicolumn{3}{|l|}{ Upper } \\
\hline Molar & 10 & 32.26 \\
\hline Lower Anterior & 2 & 6.45 \\
\hline Lower Premolar & 2 & 6.45 \\
\hline Lower Molar & 11 & 35.48 \\
\hline \multicolumn{3}{|c|}{ Removing broken instruments from root canals } \\
\hline Upper Premolar & 1 & 8.33 \\
\hline Upper Molar & 7 & 58.33 \\
\hline Lower Molar & 4 & 33.33 \\
\hline \multicolumn{3}{|l|}{ Retreatment } \\
\hline Upper Molar & 24 & 82.76 \\
\hline Lower Molar & 5 & 17.24 \\
\hline \multicolumn{3}{|c|}{ Obturation of root canals } \\
\hline Upper Premolar & 1 & 4.35 \\
\hline Upper Molar & 19 & 82.61 \\
\hline Lower Molar & 3 & 13.04 \\
\hline \multicolumn{3}{|c|}{ Irrigation of root canals } \\
\hline Upper Molar & 7 & 100.00 \\
\hline \multicolumn{3}{|c|}{ Restoration of endodontically treated teeth } \\
\hline Upper Anterior & 5 & 41.67 \\
\hline Upper Molar & 5 & 41.67 \\
\hline Lower Molar & 2 & 16.67 \\
\hline
\end{tabular}

portunity to enhance their clinical skills as much as possible at the final year of their education before they start to work in public. An integrated clinical system is instilled where a student is responsible of all the dental treatment of a patient assigned to him/her.(2) Also, a senior student is expected to complete endodontic treatments of 12 roots. Previously, this number was higher; however with some improvements made during the curriculum, this number was lowered to focus more on quality rather than quantity.
This study had a high questionnaire response rate of $80 \%$ which was adequate to provide meaningful data. Variability exists in the literature in terms of return rates of questionnaires ranging between 47 to $100 \% .^{[1,4,5]}$ This could depend on the way the questionnaire is presented (e-mail, letter, in the classroom or clinic). In this study, the questionnaires were distributed to students whilst they were working at the integrated clinic. In case questionnaires are conveyed in ways other than the clinical environment, such as via e-mails or letters, participants may feel reluctant in answering and returning, resulting in a low response rate. However; a clinical environment is a location where participants may feel more enthusiastic to make some kind of contribution.

The students were asked a total number of 10 questions as seen on the tables on a difficulty scale of 1-5 and they also selected the group of teeth from the list if their answer was different from scale 1 . A more extensive list of procedures may have resulted in a lower response rate or lack of concentration in answering the questionnaire. ${ }^{[4]}$

When summarizing the results of the study, it is observed that molars are the most difficult teeth group for all steps of endodontic treatment. This is not unexpected while many studies show that molar endodontics was a complex procedure in which the students had least confidence. ${ }^{[4,6-8]}$

Endodontic treatment of upper molars may pose difficulty both in terms of their location which does not allow to see directly and morphological characteristics. ${ }^{[2]}$ Maxillary molars were also determined to be difficult teeth for procedures such as using rubber dam, finding canal orifice and retreatment in the present study. In addition, lower molars were indicated to be difficult in terms of obtaining local anesthesia by $100 \%$ of the students, which is also consistent with the literature. It has been reported by some authors that failure in inferior alveolar nerve block anesthesia is observed with a percentage between $44 \%$ and $81 \%$ in patients with irreversible pulpitis. ${ }^{[9-11]}$

On the other hand, the students were found to be confident in using rotary systems, filling root canals, irrigation and restoration after root canal treatment.

Removing broken files from root canal is one of the challenging procedures in endodontic treatment. According to our results, most of the students $(65 \%)$ had not yet encountered such a situation at the student clinic. This is rather an expected result as retrieval of broken instruments are generally referred to the post-graduate clinics to be managed rather than undergraduate clinics.

This study focused on only the senior students of Yeditepe University. Further research is required that in- 
cludes other clinical classes as well as post-graduate students to obtain more reliable information on the clinical program of the evaluated faculty. ${ }^{[4,5,12]}$ In the meantime, the survey can be disseminated to other dental schools to make comparisons and make necessary plans for the improvement of the clinical content and curriculum. ${ }^{[13,14]}$

\section{Conclusion}

Further research comprising other schools is warranted to identify the weak areas during endodontic treatment in order to bring resolutions for the delivery of skills during endodontic procedures.

Conflics of Interest: No conflicts declared.

\section{References}

1. Martins RC, Seijo MO, Ferreira EF, Paiva SM, Ribeiro Sobrinho AP. Dental students' perceptions about the endodontic treatments performed using $\mathrm{NiTi}$ rotary instruments and hand stainless steel files. Braz Dent J 2012;23:729-36.

2. Tanalp J, Güven EP, Oktay I. Evaluation of dental students' perception and self-confidence levels regarding endodontic treatment. Eur J Dent 2013;7:218-24.

3. Mirza MB. Difficulties Encountered during Transition from Preclinical to Clinical Endodontics among Salman bin Abdul Aziz University Dental Students. J Int Oral Health 2015;7(Suppl 1):22-7.

4. Honey J, Lynch CD, Burke FM, Gilmour AS. Ready for practice? A study of confidence levels of final year dental students at Cardiff University and University College Cork. Eur J Dent Educ 2011;15:98-103.

5. Davey J, Bryant ST, Dummer PM. The confidence of un- dergraduate dental students when performing root canal treatment and their perception of the quality of endodontic education. Eur J Dent Educ 2015;19:229-34.

6. Holmes DC, Diaz-Arnold AM, Williams VD. Alumni self-perception of competence at time of dental school graduation. J Dent Educ 1997;61:465-72.

7. Patel J, Fox K, Grieveson B, Youngson CC. Undergraduate training as preparation for vocational training in England: a survey of vocational dental practitioners' and their trainers' views. Br Dent J 2006;Suppl:9-15.

8. Bartlett DW, Coward PY, Wilson R, Goodsman D, Darby $\mathrm{J}$. Experiences and perceptions of vocational training reported by the 1999 cohort of vocational dental practitioners and their trainers in England and Wales. Br Dent J 2001;191:265,70.

9. Cohen HP, Cha BY, Spångberg LS. Endodontic anesthesia in mandibular molars: a clinical study. J Endod 1993;19:370-3.

10. Claffey E, Reader A, Nusstein J, Beck M, Weaver J. Anesthetic efficacy of articaine for inferior alveolar nerve blocks in patients with irreversible pulpitis. J Endod 2004;30:568-71.

11. Bigby J, Reader A, Nusstein J, Beck M. Anesthetic efficacy of lidocaine/meperidine for inferior alveolar nerve blocks in patients with irreversible pulpitis. J Endod 2007;33:7-10.

12. Murray CM, Chandler NP. Undergraduate endodontic teaching in New Zealand: students' experience, perceptions and self-confidence levels. Aust Endod J 2014;40:116-22.

13. Henzi D, Davis E, Jasinevicius R, Hendricson W. North American dental students' perspectives about their clinical education. J Dent Educ 2006;70:361-77.

14. Gatley S, Hayes J, Davies C. Requirements, in terms of root canal treatment, of undergraduates in the European Union: an audit of teaching practice. Br Dent J 2009;207:165-70. 